\title{
Perspectives of primary health care physicians on diagnosing and referring patients with apparent osteolytic lesions on plain X-ray films: a cross- sectional study
}

\author{
This article was published in the following Dove Press journal: \\ Advances in Medical Education and Practice \\ 7 March 2016 \\ Number of times this article has been viewed
}

\author{
Ali Alyami ${ }^{1,2}$ \\ Yasser Alshomrani ${ }^{1,3}$ \\ Rayyan Suqaty' \\ Shaddy Futtiny' \\ Faisal Alnaqib' \\ Muath Albarakati ${ }^{\prime}$ \\ Ahmad Alhazmi ${ }^{1,4}$ \\ 'King Abdullah International Medical \\ Research Center, Jeddah, ${ }^{2}$ Department \\ of Orthopaedic Surgery, College of \\ Medicine, King Saud Bin Abdul-Aziz \\ University for Health Science, Jeddah, \\ ${ }^{3}$ Department of Orthopaedic Surgery, \\ ${ }^{4}$ Department of Surgery, Faculty of \\ Medicine, Umm Alqura University, \\ Makkah, Saudi Arabia
}

Background and objectives: The identification and diagnosis of musculoskeletal symptoms are major challenges for primary care physicians. A lack of clinical suspicion, limited exposure, and referral of patients to nonspecialized centers can delay the management of cases, which in turn can increase morbidity and mortality.

Subjects and methods: Four different sets of X-ray films were shown to 91 primary health care physicians. The first two were normal, whereas the third and fourth showed bone lesions. Participants were asked to indicate the presence of an abnormality, the diagnosis, and the approach to referral if required.

Results: There was a variation in the results for the first two sets of normal X-ray films. Most participants (73.6\%) were able to diagnose the first case correctly. However, $73.6 \%$ of participants were unable to diagnose the second case correctly. A high percentage of participants $(90.1 \%)$ were able to detect abnormalities in Cases 3 and 4, with nearly all participants indicating that they would refer patients to centers other than bone oncology centers in the western region of Saudi Arabia if they suspected bone tumors. Only 25.8\% of participants were aware of these bone oncology centers.

Conclusion: Physicians in many primary health care centers need practice in reading normal X-ray films to avoid unnecessary referral of patients to specialized medical centers. We recommend the development of a new system for referring patients suspected to have bone tumors to avoid a delay in the management of cases and to decrease morbidity and mortality.

Keywords: primary health care physicians, diagnosis, referral, osteolytic, lesion, X-ray film

\section{Introduction}

Musculoskeletal symptoms are common among people in various age groups, and account for up to $20 \%$ of complaints responsible for visits to primary care practitioners. ${ }^{1}$ Identification and diagnosis of these complaints are major challenges for primary care workers. ${ }^{2}$

One such complaint is bone tumors. These can be primary or secondary tumors, and the primary tumors can be either benign or malignant. ${ }^{3}$ Although such tumors are not very common, when they do occur, they cause significant morbidity and mortality. ${ }^{4}$ Benign bone tumors are usually diagnosed incidentally and can be recognized on plain radiography, without the need for additional studies, which are unnecessary and sometimes invasive. ${ }^{5}$ On the other hand, malignant bone tumors are usually detected in the elderly and are often diagnosed as skeletal metastases, commonly from prostate
Correspondence: Yasser Alshomrani Department of Orthopaedic Surgery, Faculty of Medicine, Umm Alqura University, PO Box 71709, Jeddah 21597, Saudi Arabia

EmailYasser.shom@hotmail.com (c) (1) (5) 2016 Alyami et al. This work is published and licensed by Dove Medical Press Limited. The full terms of this license are available at https://www.dovepress.com/terms. you hereby accept the Terms. Non-commercial uses of the work are permitted without any further permission from Dove Medical Press Limited, provided the work is properly attributed. For you hereby accept the Terms. Non-commercial uses of the work are permitted without any further permission from Dove Medical Press
permission for commercial use of this work, please see paragraphs 4.2 and 5 of our Terms (https.//www.dovepress.com/terms.php). 
cancer in men and breast cancer in women. ${ }^{6}$ Malignant bone tumors are aggressive and show destructive growth patterns, resulting in death in up to $50 \%$ of patients. ${ }^{3,7,8}$

Accurate patient history taking and clinical examination together with radiological investigations can help in the identification and diagnosis of bone tumors. Radiological parameters can help determine whether the tumor is benign or malignant and whether it is a primary or secondary tumor, in addition to providing other details., ${ }^{3,9}$ Primary care practitioners have limited exposure to and training in musculoskeletal medicine, lack clinical suspicion, and usually refer patients to nonspecialized centers. These factors can lead to a delay in the diagnosis of bone tumors, which in turn may increase morbidity and mortality. ${ }^{1,10}$

Radiography is an important tool in diagnosing bone tumors and tumor-like lesions. Important morphological information obtained from radiography, such as the lesion location, site within the bone, characteristics of the bone matrix, characteristics of the bone response, and soft tissue involvement, aid in the diagnosis. ${ }^{9,11,12}$ However, the misinterpretation of imaging findings is an important cause of poor outcomes in patients with bone tumors. ${ }^{13}$

The general objective of this study was to obtain a broad understanding of the perspectives of general practitioners in evaluating and managing different cases of bone tumors. The specific objectives were to explore the ability of general practitioners to detect and diagnose cases of bone tumors based on plain X-ray films and to determine the approach to referring patients with osteolytic lesions suspected to be bone tumors who visited the primary health care (PHC) centers.

\section{Materials and methods Study design and setting}

This study was designed as a cross-sectional study and was conducted between March 1 and April 20, 2015. Data were collected by using paper questionnaires distributed manually and individually to physicians in PHC centers to explore the participants' understanding and analysis of different X-ray films showing either bone lesions or normal findings.

\section{Participants}

Physicians working in PHC centers in Makkah city, the capital of the Makkah province in Saudi Arabia, in 2015-2016 for at least 3 months were included in this study. Targeted physicians are general practitioners, family medicine residents, family medicine specialists, or family medicine consultants.

\section{Measures and outcomes}

Each participant was shown four sets of bone X-ray films on a tablet computer device (IPad Tablet). The images were shown in RGB (red, green and blue) colors with dimensions of $720 \times 540$ pixels. Participants were able to zoom in or out to be able to see all details of the X-rays.

The first two sets were normal X-ray films (Figures 1 and 2). Case 3 (Figure 3) showed an osteolytic eccentric lesion at the metaphysis of the distal left tibia. Case 4 (Figure 4) showed an aggressive osteolytic-sclerotic mixed lesion at the metaphysis of the proximal right tibia.

Upon being shown the radiographic images, the general physicians had to answer three questions for each set of X-ray films: "Are the findings normal or abnormal?", "If they are abnormal, do they indicate benign or malignant pathology?", and "What is your next step?". Subsequently, the participants had to answer another three questions regarding the referral of patients with bone lesions.

\section{Sample size}

The sample size was calculated using The Survey System software with a margin of error of $5 \%$ and a confidence level of $95 \%$. The estimated sample size was 97 .

\section{Statistical analysis}

IBM SPSS software version 22.0.0 (IBM Corp., Armonk, NY, USA) was used for statistical analysis. Data are presented as percentages and frequencies. Statistical significance for some variables was tested by using the chi-squared test.

\section{Ethical considerations}

The objectives of the study were explained to the participants, and they signed consent forms prior to study entry. The research proposal was reviewed and approved by the Committee of Bio-Medical Ethics of King Saud Bin Abdul-Aziz University before the questionnaires were sent to the target population. All data were anonymized, and patient confidentiality has been maintained.

\section{Results}

Of a total of $\sim 130$ doctors in PHC centers in Makkah city, 91 responded to the questionnaire (response rate, 70\%) (Table 1).

\section{Case I}

The Case 1 images (Figure 1A and B) were considered normal by $73.6 \%$ of participants and abnormal by $20.9 \% ; 5.5 \%$ were not sure. The proportions were significantly different 
Table I Characteristics of participants

\begin{tabular}{lll}
\hline Participant's characteristics & Percentage \\
\hline Specialty & General physicians & 52.3 \\
& Family medicine residents & 18.2 \\
& Family medicine specialists & 29.5 \\
Sex & Male & 54.7 \\
Work experience & Female & 45.3 \\
& 65 years & 56.2 \\
& 6-I0 years & 26.2 \\
& II-I5 years & 12.5 \\
Place of education & In Sa years & 5 \\
& Not in Saudi Arabia & 58.8 \\
\end{tabular}

$(P<0.001 ;$ Table 2$)$. There were no significant associations between the participants' responses to the question "Are the findings normal or abnormal?" for this case and their specialty and place of education $(P>0.05)$. However, there was a significant relationship between the responses and their work experience $(P=0.013$; Table 3$)$.

\section{Case 2}

The Case 2 images (Figure 2A and B) were considered abnormal by $73.6 \%$ of participants and normal by $14.3 \% ; 12.1 \%$ were not sure. These proportions were significantly different $(P<0.001$; Table 2). There were no significant associations between the participants' responses to the question "Are the findings normal or abnormal?" for this case and their specialty, work experience, and place of education $(P>0.05$; Table 3). Physicians who considered the images abnormal were asked about the kind of abnormality they noted; $34.6 \%$ of these participants thought the abnormality was a benign lesion, $14.1 \%$ thought it was a malignant lesion, $14.1 \%$ considered another diagnosis, and $37.2 \%$ were not sure. When asked about their next step, $77.9 \%$ of participants said that they would refer this patient to a higher care center, while
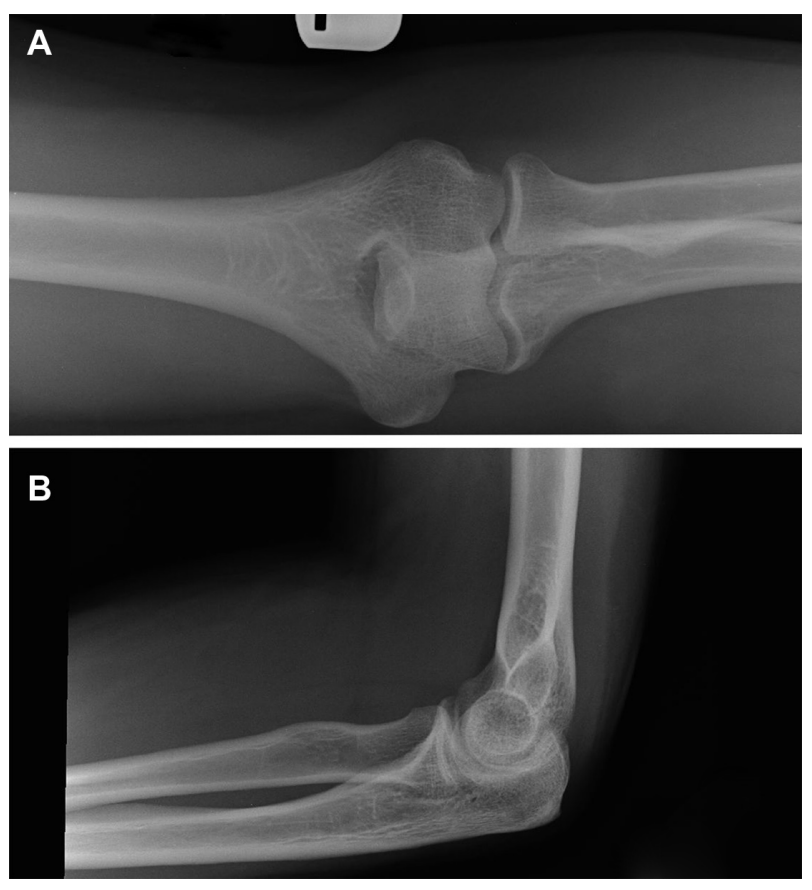

Figure 2 X-ray films for Case 2.

Notes: (A) Anteroposterior view of a normal left elbow. (B) Lateral view of a normal left elbow.

the rest of the participants said they would either reassure or manage this patient in their own center.

\section{Case 3}

The Case 3 images (Figure 3A and B) were considered abnormal by $90.1 \%$ of participants, $8.8 \%$ were not sure, and only $1.1 \%$ of participants considered the images normal. These proportions were significantly different $(P<0.001$; Table 2). There were no significant associations between the participants' responses to the question "Are the findings normal or abnormal?" for this case and their work experience and place of education $(P>0.05)$. However, there was a significant relationship with their specialty $(P=0.025$; Table 3$)$.
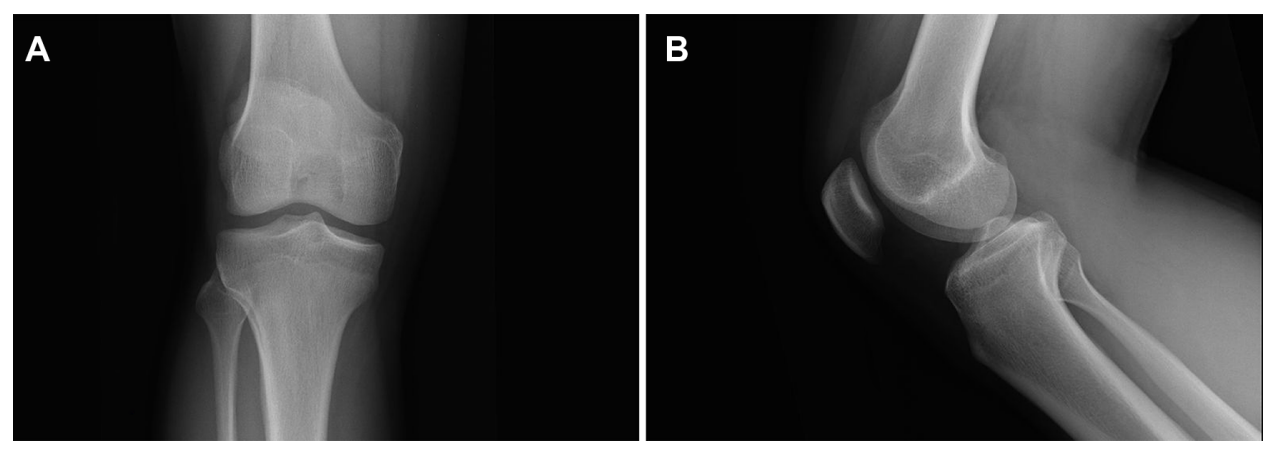

Figure I X-ray films for Case I.

Notes: (A) Anteroposterior view of a normal left knee. (B) Lateral view of a normal left knee. 
Table 2 Responses to the question "Are the findings normal or abnormal?" for the different cases

\begin{tabular}{llll}
\hline & Responses & Percentage & P-value \\
\hline Case I & Normal & 73.6 & $<0.00$ I \\
& Abnormal & 20.9 & \\
Case 2 & I am not sure & 5.5 & $<0.00$ I \\
& Normal & 14.3 & \\
Case 3 & Abnormal & 73.6 & $<0.00$ I \\
& I am not sure & 12.1 & \\
& Normal & 1.1 & $<0.00$ I \\
Case 4 & Abnormal & 90.1 & \\
& I am not sure & 8.8 & \\
& Normal & 0.0 & \\
& Abnormal & 90.1 &
\end{tabular}

Note: Statistical significance was tested using a one-way chi-squared test.

Participants who considered the images abnormal were asked about the possible pathology of the lesions; $26.1 \%$ thought the lesion was benign, $37.6 \%$ thought it was malignant, $31.8 \%$ were not sure, and $4.5 \%$ considered another diagnosis possible. With regard to their next step, $95.4 \%$ of participants said they would refer this patient immediately to a higher care center, while $4.6 \%$ said they would either reassure or treat the patient in their own center.

\section{Case 4}

The Case 4 images (Figure 4A and B) were considered abnormal by $90.1 \%$ of the participants, while $9.9 \%$ of participants were not sure $(P<0.001$; Table 2$)$. There was no significant association between the participants' responses to the question "Are the findings normal or abnormal?" for this case and their work experience or place of education $(P>0.05)$.
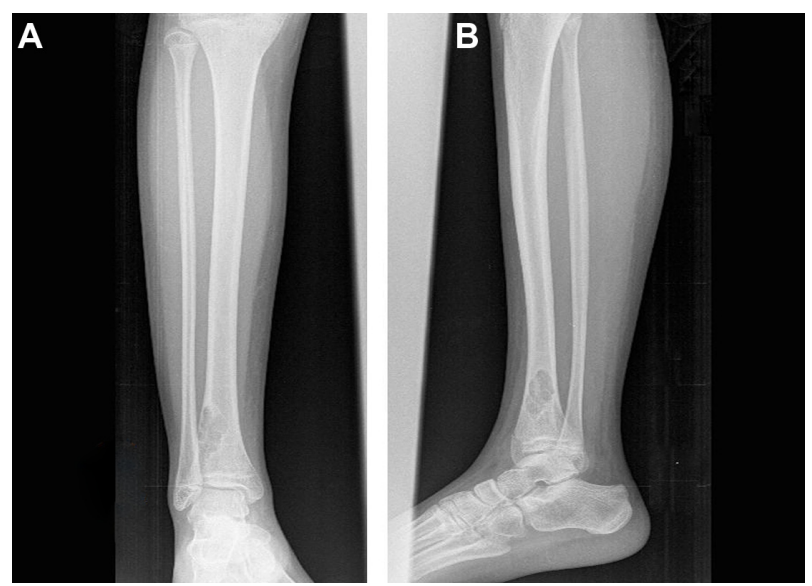

Figure 3 X-ray films for Case 3.

Notes: (A) Anteroposterior view of a left tibia showing an osteolytic eccentric lesion at the metaphysis of the distal left tibia with a well-defined sclerotic margin. There is no evidence of cortical erosion, periosteal reaction, or soft tissue extension. (B) Lateral view of a left tibia showing an osteolytic eccentric lesion at the metaphysis of the distal left tibia.

However, a significant relationship with their specialty was noted $(P=0.007$; Table 3$)$. With regard to the pathology of the lesion, $55.1 \%$ of participants considered it a malignant lesion, $15.7 \%$ considered it benign, and $29.2 \%$ were either not sure or considered another diagnosis. With regard to their next step, $91 \%$ of physicians would have immediately referred the patient to a higher care center.

\section{Perspectives on patients referral}

Of the participants who said they would refer patients with benign or malignant osteolytic lesions apparent on X-ray films to higher care centers, most (95.5\%) chose centers other than the two bone oncology centers in the western region

Table 3 The association between participant's characteristics (specialty, work experience, and place of education) and responses to the question "Are the findings normal or abnormal?" for the different cases

\begin{tabular}{|c|c|c|c|c|c|c|c|c|c|c|c|c|c|c|c|c|}
\hline \multirow{2}{*}{$\begin{array}{l}\text { Participant's } \\
\text { characteristics }\end{array}$} & \multicolumn{4}{|c|}{ Case I } & \multicolumn{4}{|c|}{ Case 2} & \multicolumn{4}{|c|}{ Case 3} & \multicolumn{4}{|c|}{ Case 4} \\
\hline & $\mathbf{N}$ & AN & NS & $P$-value & $\mathbf{N}$ & $\mathbf{A N}$ & NS & $P$-value & $\mathbf{N}$ & $\mathbf{A N}$ & NS & $P$-value & $\mathbf{N}$ & $\mathbf{A N}$ & NS & $P$-value \\
\hline \multicolumn{17}{|l|}{ Specialty } \\
\hline GP & $78.3 \%$ & $17.4 \%$ & $4.3 \%$ & 0.961 & $10.9 \%$ & $71.7 \%$ & $17.4 \%$ & 0.087 & $2.2 \%$ & $89.1 \%$ & $8.7 \%$ & 0.025 & $0.0 \%$ & $89.1 \%$ & $10.9 \%$ & 0.007 \\
\hline FMR & $69.2 \%$ & $25.0 \%$ & $6.2 \%$ & & $6.2 \%$ & $81.2 \%$ & $12.5 \%$ & & $0.0 \%$ & $93.8 \%$ & $6.2 \%$ & & $0.0 \%$ & $93.8 \%$ & $6.2 \%$ & \\
\hline FMS & $68.8 \%$ & $23.1 \%$ & $7.7 \%$ & & $19.2 \%$ & $76.9 \%$ & $3.8 \%$ & & $0.0 \%$ & $96.2 \%$ & $3.8 \%$ & & $0.0 \%$ & $96.2 \%$ & $3.8 \%$ & \\
\hline \multicolumn{17}{|c|}{ Work experience } \\
\hline$<5$ years & $77.8 \%$ & $17.8 \%$ & $4.4 \%$ & 0.013 & $13.3 \%$ & $71.1 \%$ & $15.6 \%$ & 0.583 & $2.2 \%$ & $88.9 \%$ & $8.9 \%$ & 0.691 & $0.0 \%$ & $88.9 \%$ & II.1\% & 0.373 \\
\hline $6-10$ years & $71.4 \%$ & $23.8 \%$ & $4.8 \%$ & & $4.8 \%$ & $90.5 \%$ & $4.8 \%$ & & $0.0 \%$ & $100 \%$ & $0.0 \%$ & & $0.0 \%$ & $100 \%$ & $0.0 \%$ & \\
\hline $1 \mid-15$ years & $60.0 \%$ & $40.0 \%$ & $0.0 \%$ & & $20.0 \%$ & $70.0 \%$ & $10.0 \%$ & & $0.0 \%$ & $90.0 \%$ & $10.0 \%$ & & $0.0 \%$ & $90.0 \%$ & $10.0 \%$ & \\
\hline$>15$ years & $50.0 \%$ & $0.0 \%$ & $50.0 \%$ & & $25.0 \%$ & $50.0 \%$ & $25.0 \%$ & & $0.0 \%$ & $75.0 \%$ & $25.0 \%$ & & $0.0 \%$ & $75.0 \%$ & $25.0 \%$ & \\
\hline \multicolumn{17}{|c|}{ Place of education } \\
\hline In Saudi Arabia & $72.3 \%$ & $23.4 \%$ & $4.3 \%$ & 0.750 & $8.5 \%$ & $78.7 \%$ & $12.8 \%$ & 0.520 & $2.1 \%$ & $87.2 \%$ & $10.6 \%$ & 0.438 & $0.0 \%$ & $89.4 \%$ & $10.6 \%$ & 0.491 \\
\hline Other countries & $72.7 \%$ & $18.2 \%$ & $9.1 \%$ & & $18.2 \%$ & $69.7 \%$ & $12.1 \%$ & & $0.0 \%$ & $97.0 \%$ & $3.0 \%$ & & $0.0 \%$ & $93.9 \%$ & $6.4 \%$ & \\
\hline
\end{tabular}

Note: Statistical significance was tested using a chi-squared test.

Abbreviations: N, normal; AN, abnormal; NS, not sure; GP, general physician; FMR, family medicine resident; FMS, family medicine specialist. 

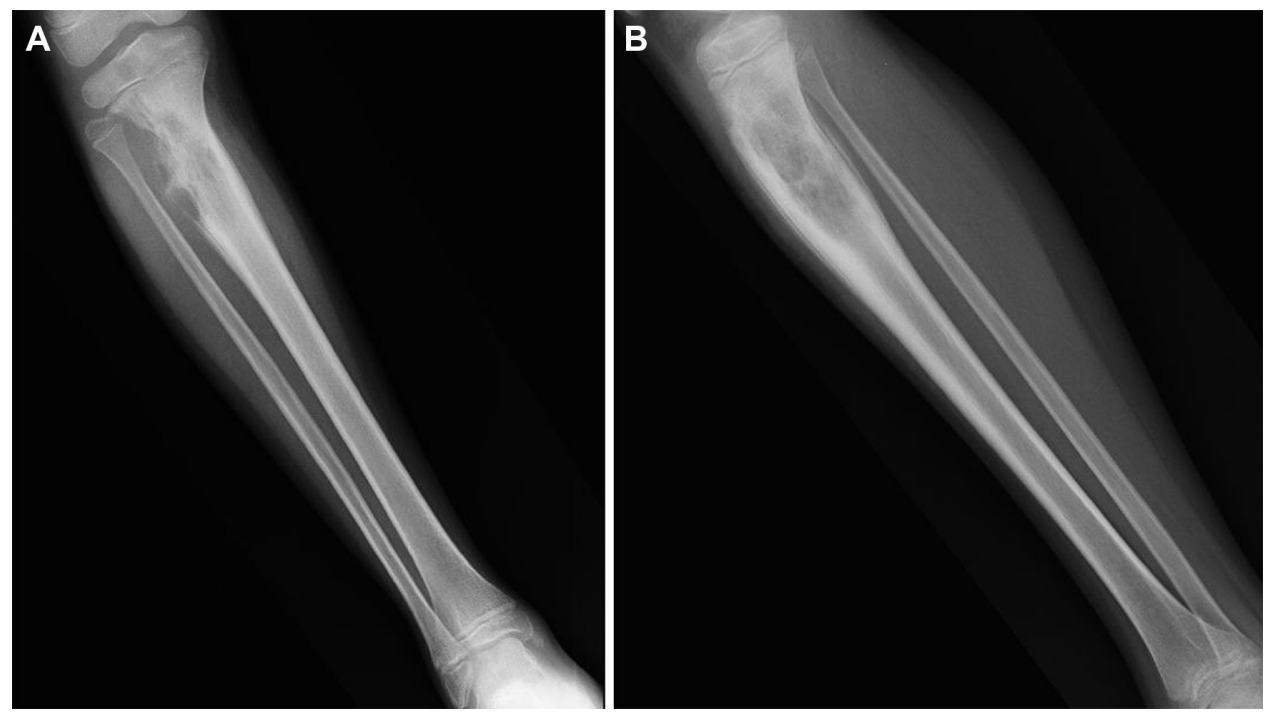

Figure 4 X-ray films for Case 4.

Notes: (A) Anteroposterior view of the right tibia of a skeletally immature patient showing an aggressive osteolytic-sclerotic mixed lesion with an ill-defined margin at the metaphysis of the proximal tibia with subtle extension to the epiphysis through the growth plate. There is lateral cortical destruction with periosteal reaction. (B) Lateral view of the right tibia of a skeletally immature patient showing an aggressive osteolytic-sclerotic mixed lesion at the metaphysis of proximal tibia.

of Saudi Arabia, while only $4.5 \%$ of participants said they would refer patients to one of these two centers (Table 4). With regard to the participants' familiarity with the bone oncology centers, $25.8 \%$ of the participants were aware of these musculoskeletal oncology centers, whereas $74.2 \%$ were not (Table 5). Of the participants who claimed to be aware of these centers, $56.2 \%$ could name only one center, $13.3 \%$ could name both, and $21.7 \%$ could not name either. There is no significant association between the participants' familiarity with the bone oncology centers and their years of practice or their different specialty $(P \geq 0.05)$.

\section{Discussion}

The main objective of our study was to explore the ability of PHC physicians to detect osteolytic lesions apparent on plain X-ray films and to determine the approach of referral to more specialized centers. We found a variation in the ability of PHC physicians to detect these osteolytic lesions.

Most participants correctly identified the Case 1 images as normal, but, unexpectedly, most participants considered

Table 4 Responses to the question "Where will you refer patients with osteolytic lesions on X-ray films suspected to be benign or malignant tumors?"

\begin{tabular}{lll}
\hline Response & Percentage & P-value \\
\hline KAMC & 3.4 & $<0.001$ \\
NGH & 1.1 & \\
Other centers & 95.5 & \\
\hline
\end{tabular}

Note: Statistical significance was tested using a one-way chi-squared test. Abbreviations: KAMC, King Abdullah Medical City; NGH, National Guard Hospital. the Case 2 images to be abnormal, which was not the case. This extreme variation in results between the first two normal cases reflects the poor ability of PHC physicians to correctly read normal bone X-ray films. A possible explanation for this is the inadequate training provided to medical students and general physicians, as stressed by Patel et al. ${ }^{1}$ Of the participants who considered the Case 1 and/or 2 images abnormal, most would have referred the patients to more advanced medical centers for additional investigations and management, which would have been unnecessary. Other studies have also reported similar results; Donald et $\mathrm{al}^{14}$ concluded that diagnostic errors based on radiological investigations are not uncommon and are mostly related to the observer's perception, whereas Taylor et $\mathrm{al}^{15}$ found that radiological diagnostic errors were multifactorial. The experience of PHC physicians may play a role in arriving at the correct diagnosis. In this study, more than half of the participants had $\leq 5$ years of work experience, and more than half of the participants were general physicians. These factors may have affected their ability to diagnose and interpret X-ray films.

Table 5 Responses to the question "Are you familiar with the musculoskeletal oncology centers in the western region of Saudi Arabia?'

\begin{tabular}{lll}
\hline Response & Percentage & P-value \\
\hline Yes & 25.8 & $<0.001$ \\
No & 74.2 & \\
\hline
\end{tabular}

Note: Statistical significance was tested using a one-way chi-squared test. 
On the other hand, Case 3 (Figure 3) showed an osteolytic eccentric lesion at the metaphysis of the distal left tibia with a well-defined sclerotic margin, $\sim 16.49 \times 40.12 \mathrm{~mm}$ in size, with no obvious matrix, cortical erosion, periosteal reaction, or soft tissue extension. These features are characteristic of nonaggressive lesions, with the most likely diagnosis being non-ossifying fibroma. The radiological diagnosis of nonossifying fibroma in this case was confirmed by pathology. According to a musculoskeletal oncology surgeon, such tumors are generally treated conservatively by observation because of the possibility of self-healing. However, in cases of painful lesions or with a high risk of fracture, curettage, bone grafting, and fixation can be performed. For Case 3 in this report, the patient was treated conservatively by observation. The lesion healed spontaneously, and the patient is doing well and has no complications.

Case 4 (Figure 4) showed an aggressive osteolytic-sclerotic mixed lesion at the metaphysis of the proximal right tibia with subtle extension into the epiphysis through the growth plate. It was $85.02 \times 22.54 \mathrm{~mm}$ in size with no matrix. Lateral cortical destruction with periosteal reaction was noted, and the lesion had an ill-defined margin. These features are typical of aggressive tumors and strongly indicate malignancy. Such cases would require magnetic resonance imaging for local staging and for planning a biopsy. Pathological examination in this case confirmed the diagnosis of Ewing sarcoma. Staging was performed and showed no evidence of metastasis. The patient was started on neoadjuvant chemotherapy, which was followed by wide surgical resection, reconstruction, postoperative chemotherapy, and extensive physiotherapy so that the patient could resume normal activities.

Most participants (91\%-95\%) stated that they would have immediately referred Cases 3 and 4 to higher care centers. However, most of them would have referred these patients to centers other than the bone oncology centers in the western region of Saudi Arabia. In fact, only a quarter of the participants were aware of these musculoskeletal oncology centers. This would have affected the immediate care of the patients, leading to a delay in appropriate management and increasing morbidity and mortality. George et $\mathrm{al}^{10}$ and Ashwood et $\mathrm{al}^{16}$ also reported a significant delay in the referral of patients with malignant bone tumors. Our results might be explained by the fact that most PHC centers in Saudi Arabia have their own policy for patient referral, with physicians referring all patients to a single tertiary center, even if it does not have the specialty required for the diagnosis. Additional studies should be conducted to address the issue of delay and to determine whether the current guidelines are adequate for making the right referral decision.
Our study has some limitations. Most importantly, the questionnaires were completed by the participants on their own, in separate locations. Hence, the interpretation might have differed. Ideally, the study should have been conducted at a single site under supervision. However, this was not done because it was too difficult to coordinate and get all participants together on a given date.

\section{Recommendations}

- Physicians at PHC centers need to practice viewing normal X-ray films to avoid unnecessary referral of patients to specialized medical centers.

- Future studies should quantify the delay in treatment of patients referred to specialized medical centers unnecessarily in order to develop new recommendations for decreasing this delay time.

- A new system for the referral of patients with suspected bone tumors should be developed to avoid a delay in their management and to decrease morbidity and mortality.

- Future studies should include a larger area, for example, the entire Makkah province, to obtain more precise results. Further, a larger number of cases should be studied, and a scoring system should be created for the answers.

\section{Acknowledgments}

The authors would like to thank Dr Zahid Altaf for his input on radiological opinions. Furthermore, the authors would like to thank the following people who helped with data collection: M Basuony, A Jalal, R Magliah, B Allugmani, M Albakri, J Alsaedi, M Shaheen, K Alhazmi, M Alhuthali, and A Alahmadi.

\section{Disclosure}

The authors report no conflicts of interest in this work.

\section{References}

1. Patel DR, Moore MD, Greydanus DE. Musculoskeletal diagnosis in adolescents. Adolesc Med State Art Rev. 2007;18(1):1-10, vii.

2. Miller BJ, Avedian RS, Rajani R, et al; Musculoskeletal Oncology Research Initiative. What is the use of imaging before referral to orthopaedic oncologist? A prospective, multicenter investigation. Clin Orthop Relat Res. 2015;473(3):868-874.

3. Gösling T, Probst C, Länger F, Rosenthal H, Brunnemer U, Krettek C. Diagnostics and treatment of primary bone tumors. Chirurg. 2010;81(7): 657-678.

4. Ries LAG, Smith MA, Gurney JG, et al. Cancer incidence and survival among children and adolescents: United States SEER Program 1975-1995, National Cancer Institute, SEER Program. NIH Pub. No. 99-4649. Bethesda, MD: NIH; 1999.

5. Yildiz C, Erler K, Atesalp AS, Basbozkurt M. Benign bone tumors in children. Curr Opin Pediatr. 2003;15(1):58-67.

6. Scutellari PN, Antinolfi G, Galeotti R, Giganti M. Metastatic bone disease. Strategies for imaging. Minerva Med. 2003;94(2):77-90. 
7. Hillmann A, Gösling T. Benign bone tumors: general principles. Unfallchirurg. 2014;117(10):873-882.

8. Siegel R, Ma J, Zou Z, Jemal A. Cancer statistics, 2014. CA Cancer J Clin. 2014;64(1):9-29.

9. Priolo F, Cerase A. The current role of radiography in the assessment of skeletal tumors and tumor-like lesions. Eur J Radiol. 1998;27 Suppl 1: S77-S85.

10. George A, Grimer R. Early symptoms of bone and soft tissue sarcomas: could they be diagnosed earlier? Ann R Coll Surg Engl. 2012;94(4):261-266.

11. Wiens J. Benign bone tumors and tumor-like lesions: what must clinicians know about imaging? Unfallchirurg. 2014;117(10):863-872.
12. Söderlund V. Radiological diagnosis of skeletal metastasis. Eur Radiol. 1996;6(5):587-595.

13. Campanacci M, Mercuri M, Gasbarrini A, Campanacci L. The value of imaging in the diagnosis and treatment of bone tumors. Eur J Radiol. 1998;27 Suppl 1:S116-S22.

14. Donald JJ, Barnard SA. Common patterns in 558 diagnostic radiology errors. J Med Imaging Radiat Oncol. 2012;56(2):173-178.

15. Taylor GA, Voss SD, Melvin PR, Graham DA. Diagnostic errors in pediatric radiology. Pediatr Radiol. 2011;41(3):327-334.

16. Ashwood N, Witt JD, Hallam PJ, Cobb JP. Analysis of the referral pattern to a supraregional bone and soft tissue tumour service. Ann R Coll Surg Engl. 2003;85(4):272-276.

\section{Publish your work in this journal}

Advances in Medical Education and Practice is an international, peerreviewed, open access journal that aims to present and publish research on Medical Education covering medical, dental, nursing and allied health care professional education. The journal covers undergraduate education, postgraduate training and continuing medical education including emerging trends and innovative models linking education, research, and health care services. The manuscript management system is completely online and includes a very quick and fair peer-review system. Visit http://www.dovepress.com/testimonials.php to read real quotes from published authors.

Submit your manuscript here: http://www.dovepress.com/advances-in-medical-education-and-practice-journal 